\title{
Post-traumatic ossifications of the rectum femoris: Arthroscopic treatment and clinical outcome after 2 years
}

\author{
Raul Zini ${ }^{\mathrm{a}}$, Manlio Panascì ${ }^{\mathrm{b}, *}$ \\ a Maria Cecilia Hospital, GVM Care and Research, Ravenna, Italy \\ ' San Carlo di Nancy Hospital, GVM Care and Research, Rome, Italy
}

\section{A R T I C L E I N F O}

\section{Article history:}

Received 24 June 2018

Received in revised form 29 September 2018 Accepted 30 September 2018

\section{Keywords:}

hip

rectus femoris

groin pain

arthroscopy

sport-injury

\begin{abstract}
A B S T R A C T
Injuries of the rectus femoris tendon origin could result in a chronic tendinopathy, leading to groin pain and loss of function.

Conservative treatment with analgesics and physical therapy is the gold standard, but in some cases excessive bone formation after avulsion injuries, can lead to a post-traumatic heterotopic ossification (PHO) and may benefit from surgical removal.

Methods: Outcome was evaluated in 16 top soccer players (age 24-43 years) affected by calcification of the proximal rectus who underwent arthroscopic excision (6-12 and 24 months). X-ray and 3D CT was collected for all patients. Hip disability and Osteoarthritis Outcome Score, Oxford Hip Score, Modified Harris Hip Score, together with visual analog scales (VAS) for pain, sport activity level (SAL), and activities of daily living (ADL) were used to evaluate clinical outcome.

Technical procedure: after central compartment examination and treatment was accomplished, attention was focused to the ossification of the rectus femoris. A complete exposure of the ossification was achieved; when possible attention was taken in detaching the minimum amount of fibers of the direct head of the rectus femoris from its insertion site. During the entire procedure, both dynamic direct visualization and fluoroscopic evaluation of the amount of resection were performed.

Results: Clinical outcome was excellent; the percentage of return to pre-injury level sport was $68.75 \%$ (11 athletes), with significant statistical improvement of MHHS, OHS and all 3 VAS subscales in all patients at 2 years follow-up.

Conclusion: Arthroscopic removal using conventional hip arthroscopic portals represent both effective and safe procedure to adequately treat post-traumatic ossification of the rectus femoris.
\end{abstract}

(c) 2018 Elsevier Ltd. All rights reserved.

\section{Introduction}

Post-traumatic heterotopic ossification (PHO) of the rectus femoris can be very disabling in athletes, with most injuries occurring at the myotendinous junction. Most of these injuries can be successfully managed with conservative treatment. Hip arthroscopic surgical techniques around the hip joint have become very common, addressing peritrochanteric disord S. eep gluteal syndrome, and hamstring tendon tear. $[1,7,11,23,29]$. The focus of this retrospective case-series studv is to evaluate longer-term results from our previous study of arthroscopic approach to treat $\mathrm{PHO}$ of the rectus femoris [3T].

\footnotetext{
* Corresponding author.

E-mail address: studiopanasci@gmail.com (M. Panascì).
}

\section{Materials and Methods}

Sixteen consecutive male patients presented to Our institution between September 2009 and July 2015 for chronic (>6 months) pain and impaired function of the hip, unresponsive to nonsteroidal anti-inflammatory drugs (NSAIDs) and physical therapy. All patients were soccer players. None had a history of previous hip issues or

other significant recorded trauma. Patients complained of pain at the anterior aspect of the hip, limited hip extension. A standard radiograph showed a $\mathrm{PHO}$ close to the superior aspect of the acetabulum. (Figs. 1 and 2 ) A computed tomography scan was performed in all patients, which confirmed the presence of a calcification of the direct head of the rectus femoris. Patients were therefore indicated for arthroscopic excision of the PTO. 


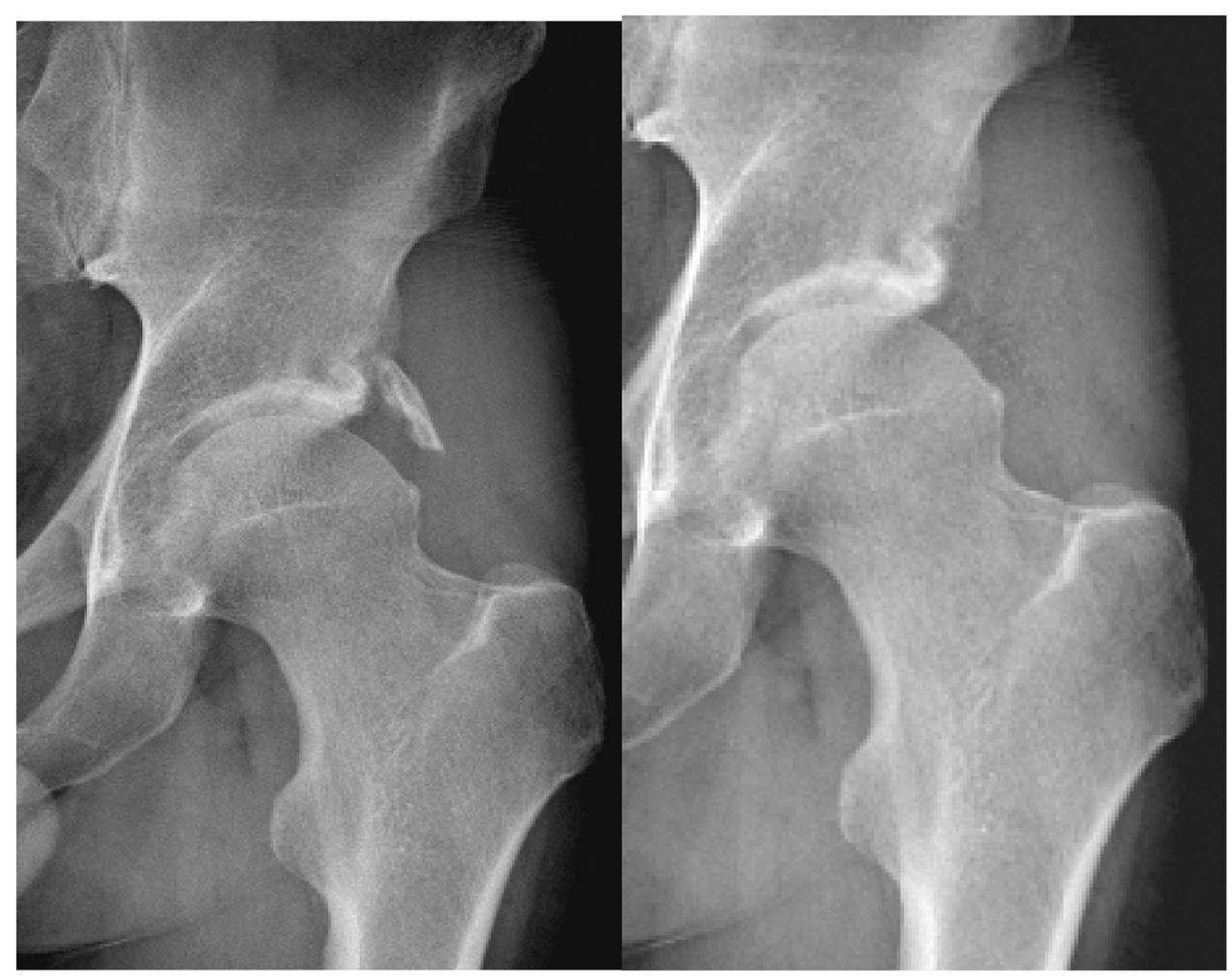

Fig. 1 and 2. Image showing ossification of the rectus femoris. Post-op x-ray showing complete excision of the PHO.

\section{Statistical Analysis}

Preoperative and postoperative values were expressed as median and $95 \% \mathrm{CI}$, and were compared using the Wilcoxon paired samples test. The level of statistical significance was set at $\mathrm{p}<0.050$. Data analyses were performed using STATA v.11 (StataCorp, College Station, TX).

\section{Outcome Evaluation}

To evaluate the outcome, pre- and postoperative (6,12 and 24 months) standardized hip rating scores were used: the Hip disability and Osteoarthritis Outcome Score (HOOS) [25] Oxford Hip Score (OHS) [9], and modified Harris Hip Score (mHHS)[]. Moreover, visual analog scales (VASs) were used for pain, sport activity level (SAL), and activities of daily living (ADL), expressed as a subjective value between 0 and 100 ( $100=$ pre-injury sport level, 0 = inability to play sport) (Table 1 ).

\section{Surgical Technique}

A standard fracture table was used with the patient in a supine position [4]. The operative limb was placed with the hip in slight abduction and internal rotation. The contralateral limb was positioned in extension and neutral rotation, with the foot in a support applying a counterbalancing traction. Countertraction, lateralized toward the operative hip, was placed in the perineal region. Two standard portals were used. Using the $70^{\circ}$ arthroscope, the anterolateral portal (ALP) was performed. The ALP provides a complete view of the central compartment for the treatment of possible associated intra-articular pathologies. Once inside the hip joint with the camera through the ALP, the mid-anterior portal was created via direct visualization. An arthroscopic knife (Samurai blade; Stryker) was introduced to perform an interportal capsulotomy parallel to the labrum. Coagulation of bleeding vessels was achieved with a radiofrequency device (Smith \& Nephew). The central compartment was addressed first.

Table 1

Pre- and Postoperative Pain and Function Scores ${ }^{a}$

\begin{tabular}{|c|c|c|c|c|c|}
\hline \multirow[t]{2}{*}{ Measure } & \multirow[t]{2}{*}{ Preoperative (Mean \pm SD) } & \multicolumn{2}{|l|}{ Postoperative } & \multicolumn{2}{|l|}{$P$ Value } \\
\hline & & 6 Months (Mean \pm SD) & 12 Months $($ Mean \pm SD) & 24 Months Mena \pm SD) & Preoperative vs 24 Months \\
\hline HOOS & $44.4 \pm 24.0$ & $77.7 \pm 7.2$ & $91.1 \pm 8.0$ & $90.1 \pm 8.0$ & $<.05$ \\
\hline mHHS & $70.8 \pm 6.0$ & $86.9 \pm 9.3$ & $96.9 \pm 4.4$ & $97.9 \pm 4.4$ & $<.05$ \\
\hline OHS & $37.5 \pm 5.0$ & $40.2 \pm 2.1$ & $46.5 \pm 0.8$ & $47.5 \pm 0.8$ & $<.05$ \\
\hline \multicolumn{6}{|l|}{ VAS } \\
\hline Pain & $4.3 \pm 1.1$ & $2.3 \pm 1.1$ & $0.2 \pm 0.4$ & $<0.2 \pm 0.4$ & $<.05$ \\
\hline ADL & $71.6 \pm 14.6$ & 80 & $98.3 \pm 3.7$ & $98.4 \pm 3.5$ & $<.05$ \\
\hline SAL & $18.3 \pm 26.0$ & $71.6 \pm 6$ & $91.6 \pm 8.9$ & $90.4 \pm 8.4$ & $<.05$ \\
\hline
\end{tabular}

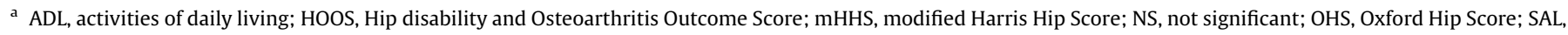
sport activity level; VAS, visual analog scale. 
Concomitant lesions (labral tear, chondral lesion, impingement) were evaluated and eventually treated. After central compartment examination and treatment was completed, the traction was removed and attention was focused to the calcification of the rectus femoris. A shaver was used to clear all soft tissue from the overhanging acetabulum and to better delimit the plane between the acetabular rim and the calcification. Using an extra-long, 5.5$\mathrm{mm}$ full-radius shaver and a radiofrequency device, complete exposure of the calcification was achieved (Fig. 3). When possible, care was taken in detaching the minimum amount of fibers of the direct head of the rectus femoris from its insertion site. Using the image intensifier as a guide, the calcification was removed using a 5.5-mm bur (Figs. 4-6). During the entire procedure, both dynamic direct visualization and fluoroscopic evaluation of the amount of resection were performed. Patients were discharged the day after the procedure. Weight-bearing was permitted as tolerated, but the extension of the hip was forbidden for 3 weeks to avoid excessive elongation of the rectus femoris tendon. To avoid recurrence, a course of celecoxib was prescribed ( $200 \mathrm{mg} / \mathrm{d}$ for 4 weeks).

\section{Results}

The average age of the patients was 26,6 years (range, 24-43 years). The mean time from symptoms to surgery was 10.2 months. After surgery, all patients reported satisfactory outcomes, with 11 of 18 patients rating their return to sport level as high as pre-injury $(P<.05)$, and the remaining 6 returned at a percentage above $80 \%$ according to the SAL score at a mean of 8 weeks (range, 4-9 weeks) from surgery. Seventeen of 18 patients ranked their ability to carry on daily activities as $100 \%$. The minimum follow-up was 24 months. The mean time to sport activity return was 42.8 days. Comparing pre- with postoperative values at 2 year from surgery, the statistical analysis showed significant improvement for HOOS (mean, 90.1 \pm 8 ), OHS (mean, $47.5 \pm 0.8$ ), mHHS (mean, $97.9 \pm 4.4$ ), and the VAS for pain (mean, $0.2 \pm 0.4$ ), ADL (mean, $98.4 \pm 3.5$ ), and SAL (mean, $90.4 \pm 8.4$ ) from pre- to postoperative $(P<.05)$.

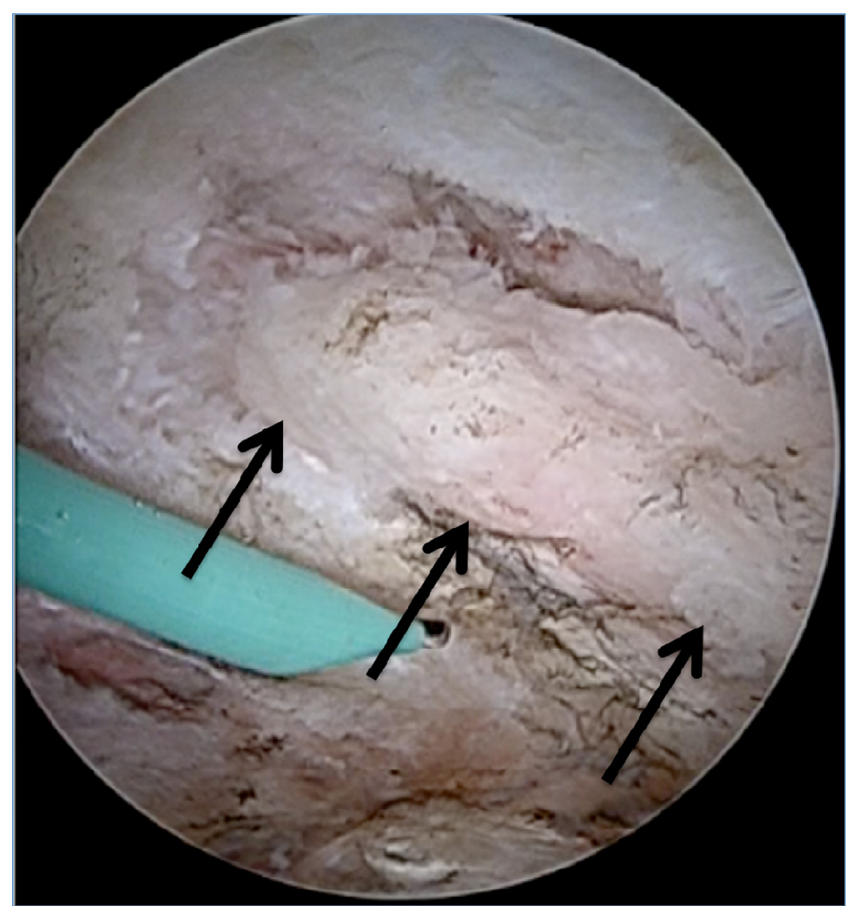

Fig. 3. Complete exposure of the post-traumatic Heterotopic ossification of the rectus femoris.

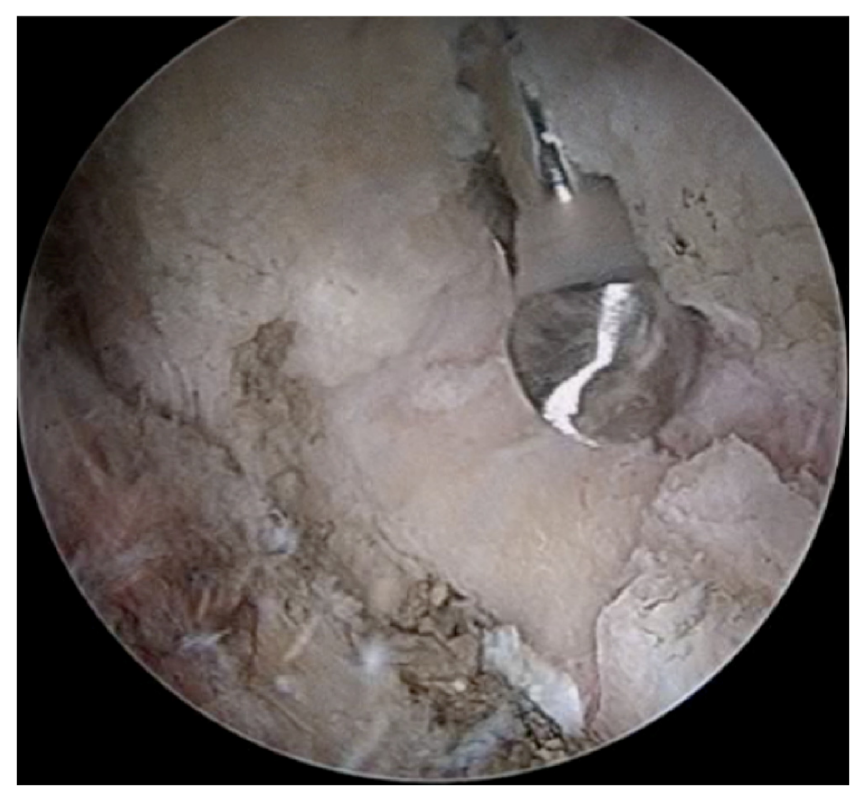

Fig. 4. Arthroscopic views during rectus femoris ossification removal.

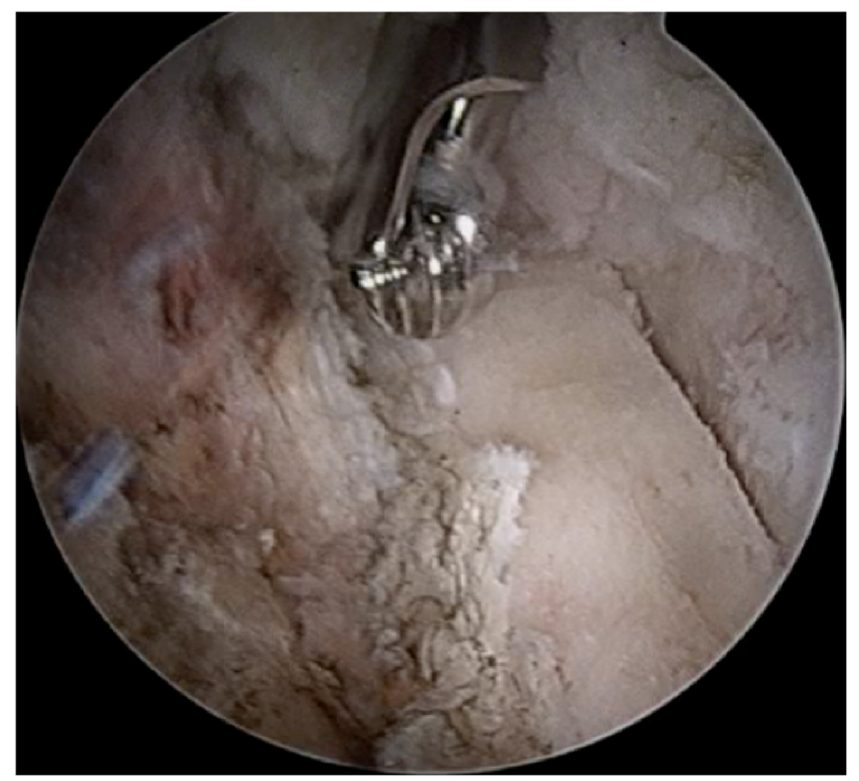

Fig. 5. Arthroscopic views during rectus femoris ossification removal.

\section{Discussion}

A PHO of the rectus femoris tendon is a rare condition, mos affecting athletes, that can cause hip pain and impairment [1 2 . Other possible causes of hip pain coming from rectus femoris origin include os acetabuli, avulsion fractures, and myositis ossificans [17,29]. Generally, a calcific deposit within the tendon of the rectus femoris can be visualized on radiograph as a formation usually parallel to the long axis of the femur (see Figure1 Fig. 1). Various etiopathogenetic hyr ses have been proposed, such as consequence of a previous in 30]. Local stress necrosis [6] has been suggested as the first step for the deposition of calcium salts, either directly or through fatty acid and soap intermediaries. A more recent theory proposed the role of local hypoxia as a cause secondary to either mechanical or vascular 


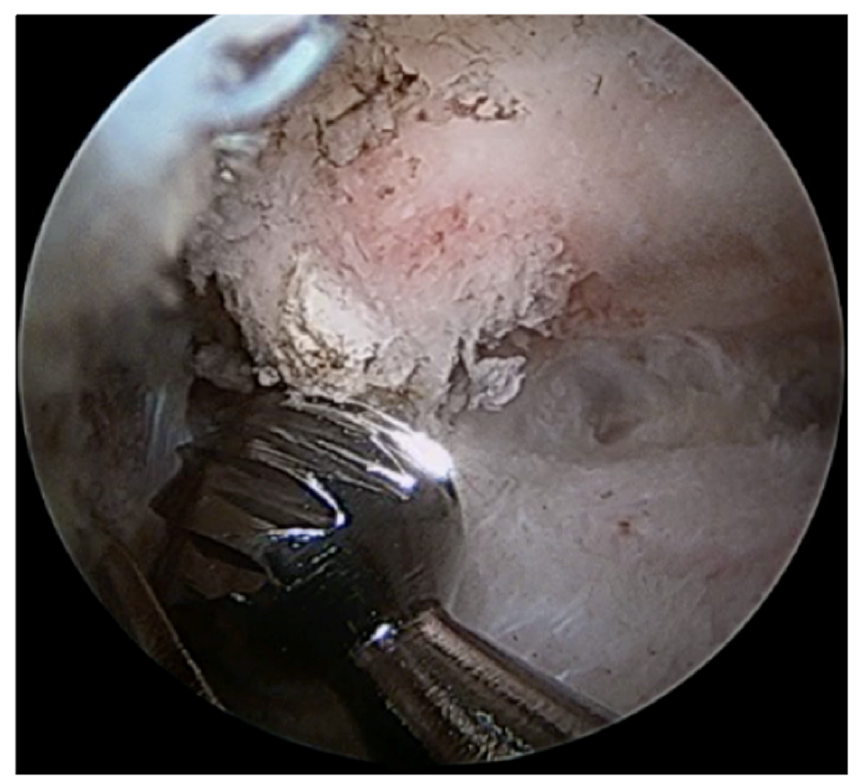

Fig. 6. Arthroscopic views during rectus femoris ossification removal.

factors [29]. In this series, 2 cases presented the tendon calcification together with a labral tear. A relatively recent paper described a new pathological entity, the hip anterosuperior labral tear with avulsion of rectus femoris (HALTAR) [19].

Traditional treatment for calcific tendinitis of rectus femoris included oral NSAIDs [18,27], and previously, radiotherapy [21]. All the treatment options give the possibility of recovery from symptoms. In refractory cases or when a large bone formation occurs (ie, traumatic injuries), a surgical excision of the calcification may be necessary, traditionally performed through an anterior approach [3]. Hip arthroscopy has given the opportunity to reduce tissue damage and have a faster recovery. In addition, it allows concomitant intra- and extra-articular disorders such us a femoroacetabular impingement to be addressed.

This is to our knowledge the largest published series of rectus femoris tendon calcification in top amateur athletes (soccer players) to date with a follow up of at least 24 months. ElHusseiny et al. [12] reported 1 case of arthroscopic excision of heterotopic ossification in a chronic rectus femoris origin injury. The patient was pain-free and able to return to full training within 8 weeks. Peng et al. [26] reported on 3 patients (age range, 38-55 years) affected by a calcific tendinitis of the rectus femoris tendon addressed using arthroscopic excision. At 9month follow-up, all 3 patients were pain-free and had recovered full function. A recent study showed a good clinical outcome using the endoscopic approach to remove the ossification. We think this is a valid surgical option in cases where a central compartment evaluation is not necessary, although no data are evaluable to compare it with a traditional trans-capsular approach in terms of time recovery, complications or recurrence rate [7].

Limitations of the study include the small number of patients and the fact that it was a retrospective study. No complications were reported during the follow-up period, patients needed a short hospitalization (1 night) and immediately started rehabilitation. As a minimally invasive surgery, the main advantages of hip arthroscopy are minimal damage to the soft tissues surrounding the hip area and rapid recovery [13]. In addition, it provides the opportunity to address concomitant lesions, such as labral tear, femoro-acetabular impingement, and cartilage lesions [2,13].

\section{Conclusion}

Post-traumatic ossification of the rectus femoris is associated with sports involving powerful and repetitive hip movement through full the range of motion. The arthroscopic approach can be considered a feasible and effective option, with few risks for the patients, rapid recovery, and improved results at long-term follow-up.

\section{Conflict of interest}

The authors whose names are listed immediately below certify that they have NO affi liations with or involvement in any organization or entity with any fi nancial interest (such as honoraria; educational grants; participation in speakers' bureaus; membership, employment, consultancies, stock ownership, or other equity interest; and expert testimony or patent-licensing arrangements), or non-fi nancial interest (such as personal or professional relationships, affi liations, knowledge or beliefs) in the subject matter or materials discussed in this manuscript.

\section{References}

[1] Benanti J.C., Gramling P, Bulat PI, Chen P, Lundstrom G. Retropharyngeal calcific tendinitis: report of five cases and review of the literature. J Emerg Med. 1986;4:15-24.

[2] Bozic KJ, Chan V, Valone FH. 3rd, Feeley BT, Vail TP. Trends in hip arthroscopy utilization in the United States. J Arthroplasty. 2013;28(8 suppl):140-3.

[3] Braun-Moscovici Y, Schapira D, Nahir AM. Calcific tendinitis of the rectus femoris. J Clin Rheumatol. 2006;12:298-300.

[4] Byrd JW. Hip arthroscopy utilizing the supine position. Arthroscopy. 1994;10:275-80.

[6] Carroll RE, Seitz Jr WH, Putnam MD. Acute calcium deposit in the hand of an 11-year-old girl. J Pediatr Orthop. 1985;5:468-70.

[7] Comba F, Piuzzi NS. Endoscopic Extraarticular Surgical Removal of Heterotopic Ossification of the Rectus FemorisTendon in a Series of Athletes. Orthop J Sports Med. 2016;4(September (9)).

[9] Dawson J, Fitzpatrick R, Carr A, Murray D. Questionnaire on the perceptions of patients about total hip replacement. J Bone Joint Surg Br. 1996;78:185-90.

[11] Domb BG, Nasser RM, Botser IB. Partial-thickness tears of the gluteus medius: Rationale and technique for trans-tendinous endoscopic repair. Arthroscopy. 2010;26:1697-705 [PubMed].

[12] El-Husseiny M, Sukeik M, Haddad FS. Arthroscopic excision of heterotopic calcification in a chronic rectus femoris origin injury: a case report. Ann R Coll Surg Engl. 2012;94(3):e129-131.

[13] Enseki KR, Martin RL, Draovitch P, Kelly BT, Philippon MJ, Schenker ML. The hip joint: arthroscopic procedures and postoperative rehabilitation. J Orthop Sports Phys Ther. 2006;36:516-25.

[17] Hodge JC, Schneider R, Freiberger RH, Magid SK. Calcific tendinitis in the proximal thigh. Arthritis Rheum. 1993;36:1476-82.

[18] Holt PD, Keats TE. Calcific tendinitis: a review of the usual and unusual. Skeletal Radiol. 1993;22:1-9.

[19] Hosalkar HS, Pennock AT, Zaps D, Schmitz MR, Bomar JD, Bittersohl B. The hip antero-superior labral tear with avulsion of rectus femoris (HALTAR) lesion: does the SLAP equivalent in the hip exist? Hip Int. 2012;22:391-6.

[21] King JW, Vanderpool DW. Calcific tendonitis of the rectus femoris. Am J Orthop. 1967;9:110-1.

[23] Martin HD, Shears SA, Johnson JC, Smathers AM, Palmer IJ. The endoscopic treatment of sciatic nerve entrapment/deep gluteal syndrome. Arthroscopy. $2011 ; 27: 172-81$.

[25] Ouellette H, Thomas BJ, Nelson E, Torriani M. MR imaging of rectus femoris origin injuries. Skeletal Radiol. 2006;35:665-72.

[26] Peng X, Feng Y, Chen G, Yang L. Arthroscopic treatment of chronically painful calcific tendinitis of the rectus femoris. Eur J Med Res. 2013;18:49.

[27] Pope Jr TL, Keats TE. Case report 733. Calcific tendinitis of the origin of the medial and lateral heads of the rectus femoris muscle and the anterior iliac spine (AIIS). Skeletal Radiol. 1992;21:271-2.

[29] Sarkar JS, Haddad FS, Crean SV, Brooks P. Acute calcific tendinitis of the rectus femoris. J Bone Joint Surg Br. 1996;78:814-6.

[30] Uhthoff HK, Sarkar K, Maynard JA. Calcifying tendinitis: a new concept of its pathogenesis. Clin Orthop Relat Res. 1976;(118):164-8.

[31] Zini R, Panascì M, Papalia R, Franceschi F, Vasta S, Denaro V. Rectus femoris tendon calcification: arthroscopic excision in 6 top amateur athletes. Orthop J Sports Med. 2014;2(12).

\section{Further readings}

[5] Byrd JW, Jones KS. Prospective analysis of hip arthroscopy with 2-year followup. Arthroscopy. 2000;16:578-87.

[8] Cox D, Paterson FW. Acute calcific tendinitis of peroneus longus. J Bone Joint Surg Br. 1991;73:342. 
[10] Dilley DF, Tonkin MA. Acute calcific tendinitis in the hand and wrist. J Hand Surg Br. 1991;16:215-6.

[14] Gamradt SC, Brophy RH, Barnes R, Warren RF, Thomas Byrd JW, Kelly BT. Nonoperative treatment for proximal avulsion of the rectus femoris in professional American football. Am J Sports Med. 2009;37:1370-4.

[15] Harris JD, McCormick FM, Abrams GD, et al. Complications and reoperations during and after hip arthroscopy: a systematic review of 92 studies and more than 6,000 patients. Arthroscopy. 2013;29:589-95.

[16] Hetsroni I, Larson CM, Dela Torre K, Zbeda RM, Magennis E, Kelly BT. Anterior inferior iliac spine deformity as an extra-articular source for hip impingement: a series of 10 patients treated with arthroscopic decompression. Arthroscopy. 2012;28:1644-53.
[20] Kim YS, Lee HM, Kim JP. Acute calcific tendinitis of the rectus femoris associated with intraosseous involvement: a case report with serial CT and MRI findings. Eur J Orthop Surg Traumatol. 2013;23(suppl 2):S233-9.

[22] Larson CM, Kelly BT, Stone RM. Making a case for anterior inferior iliac spine subspine hip impingement: three representative case reports and proposed concept. Arthroscopy. 2011;27:1732-7.

[24] Nilsdotter AK, Lohmander LS, Klassbo M, Roos EM. Hip disability and osteoarthritis outcome score (HOOS)-validity and responsiveness in total hip replacement. BMC Musculoskelet Disord. 2003;4:10.

[28] Polesello GC, Queiroz MC, Domb BG, Ono NK, Honda EK. Surgical technique: Endoscopic gluteus maximus tendon release for external snapping hip syndrome. Clin Orthop Relat Res. 2013;471:2471-6. 